\title{
Pencorakan Kepulauan Melayu dan Pulau Pinang oleh Kaum Jawi Peranakan dan Hadhrami Melalui Kewartawanan dan Persuratkhabaran Sebelum 1942: SATU Tafsiran Semula Penulisan W. R. Roff
}

\author{
Ahmad Murad Merican \\ Universiti Islam Antarabangsa Malaysia, Malaysia \\ ahmadmurad@iium.edu.my
}

\begin{abstract}
THE PATTERNING OF THE MALAY ARCHIPELAGO AND PENANG BY THE JAWI PERANAKANS AND HADHRAMI THROUGH JOURNALISM AND NEWSPAPERS BEFORE 1942: A REINTERPRETATION OF THE WRITINGS OF W. R. ROFF
\end{abstract}

\begin{abstract}
This article provides a reintrepretation and emphasis on journalism and newspapers, generally through the writings of W.R. Roff. Three of his works significant to this study are Studies on Islam and Society in Southeast Asia (2009: NUS Press Singapore), Bibliography of Malay and Arabic periodicals published in the Straits Settlements an Peninsular Malay States 1876-1941 (1972: Oxford University Press) and The Origins of Malay Nationalism (1967: Yale University Press). From his studies, it is instructive to recall that the Malay-language newspapers was the outcome of the collusion between the culture of the Malay archipelago and the West; and early Malay journalism from 1876 through the beginning of the Japanese Occupation in 1942 was the expression and manifestation of a Malay identity through the Jawi Peranakan and Hadhrami communities in an urban and cosmopolitan climate, with specific reference to the Tanjong Malays in Pulau Pinang.
\end{abstract}

Keywords: Malay Journalism, Jawi Peranakan, W. R. Roff, Penang

\section{PENGENALAN}

Makalah ini membincangkan ekspresi 'Melayu' ${ }^{1}$ melalui surat khabar dan kewartawanan di Kepulauan Melayu dengan rujukan khusus kepada Pulau Pinang sebelum tahun 1942. Satu tinjauan dan ulasan telah dibuat dengan tujuan memperlihatkan wajah Melayu yang ditonjolkan melalui kaum Jawi Peranakan dan Hadhrami. Sejarawan William R. Roff, walaupun tidak bertumpu dan khusus kepada Pulau Pinang, telah mempersembahkan kita kepada satu lapisan budaya dan identiti yang tidak dipedulikan oleh sarjana-sarjana Melayu 
lain yang mengkaji kewartawanan dan persuratkhabaran Melayu. Makalah ini merujuk kepada tiga penulisan Roff yang berpengaruh dalam pengajian Melayu daripada sudut sejarah politik Melayu, kewartawanan dan persuratkhabaran Melayu. Buku-buku tersebut ialah Studies on Islam and Society in Southeast Asia (2009: NUS Press Singapore), Bibliography of Malay and Arabic periodicals published in the Straits Settlements an Peninsular Malay States 1876-1941 (1972: Oxford University Press) dan The Origins of Malay Nationalism (1967: Yale University Press).

Melalui kajian-kajian beliau, dapat diperhatikan suasana kesarjanaan persuratkhabaran dan kewartawanan Melayu di tanah Melayu yang dimiliki oleh masyarakat Jawi Peranakan dan Hadhrami. Yang kita ketahui ialah surat khabar harian yang dimiliki sepenuhnya oleh orang Melayu ialah Utusan Melayu yang diterbitkan pada 29 May, 1939 (Roff, 1967: 176). Berdasarkan sejarah dan persejarahan moden Malaysia sehingga tahun 1939, kewartawanan dan surat khabar Melayu wujud sebagai satu lapisan penerbitan berbahasa Melayu, tetapi pandangan alam dikatakan tidak mewakili pemikiran Melayu. Istilah 'Jawi Peranakan,' 'Peranakan Arab' atau 'Hadrami' tidak digunakan sebagai kategori signifikan dalam persejarahan dan suasana kewartawanan dan persuratkhabaran Melayu.

Kepentingan korpus dan penulisan Roff dalam hal ini perlu dilihat dalam konteks iklim penjajahan. Kesedarannya dalam mengkaji masyarakat dan kewartawanan Melayu-Islam pada zaman itu memperlihatkan keunggulan kesarjanaannya. Dalam bab Pengenalan pada Studies on Islam and Society in Southeast Asia (2009), beliau mengakui bahawa apa-apa yang beliau sebenarnya berminat ialah "pengalaman sejarah, di bawah penjajahan, terhadap orang Melayu, tetapi saya kurang yakin jenis bahan asli yang tersedia wujud untuk seseorang penyelidik ("...the historical experience, under colonialism, of the Malay people, but I was quite uncertain what kinds of indigenous materials would be available to the researcher," Introduction, $\mathrm{h}$. xii). Dalam kajian mengenai persuratkhabaran dan kewartawanan Melayu, Roff telah berjaya menggembelingkan jalur-jalur identiti dan etnisiti yang amat rencam dengan masyarakat Melayu melalui dapatan etnografinya. Temubualnya dengan mereka yang terbabit dan jalinan bahan-bahan arkib telah menjadikan korpus Roff satu-satunya kajian yang tidak ternilai dalam memahami sesuatu zaman perjalanan hidup masyarakat Melayu. Malah, bagi mereka yang ingin memahami 'psyche' dan pandangan sarwa Melayu kini, mesti menelaah buku-buku sejarawan tersebut.

Dekad-dekad akhir 1800-an hingga Perang Dunia Kedua memperlihatkan dinamisme dan kegelisahan nilai dalam pertembungan Melayu dengan Barat. Dan dalam pada itu, terserlah prasangka Melayu terhadap kaum 'Keling' dan Arab, yang dianggap mencabar kedudukan orang-orang Melayu dalam kehidupan intelektual dan sosial di Tanah Melayu. Roff telah menggarap liku-liku pertembungan ini dengan cemerlang. Hasil dari korpus yang terbitkan oleh Roff, didapati bahawa selain dari Singapura, Pulau Pinang merupakan satusatunya tempat dan bandar pelabuhan yang menjadi pertembungan budaya dari timur dan barat serta juga dari semenanjung tanah Melayu, terutamanya dari tanah besar Kedah. Kaumkaum tersebut merupakan jelmaan² dalam kehidupan Melayu di Tanjong, Pulau Pinang. Ekspresi identiti ini mula ditonjolkan oleh surat khabar Jawi Peranakan (1876) di Singapura.

Namun, asal-usul surat khabar tersebut berakar umbi di Pulau Pinang sebelum muncul di Singapura dan sebahagian besar alam kepulauan Melayu. Malah jika diterokai konsep Pulau Pinang di Alam Melayu, manifestasi unggulnya ialah surat khabar Jawi Peranakan. Yang dapat ditafsirkan ialah persuratkhabaran dan kewartawanan di Pulau Pinang sejak tahun 1894 ialah lanjutan dari surat khabar dan kaum Jawi Peranakan dari segi citra dan 
pemikiran. Tahun tersebut memperlihatkan penerbitan dua kali seminggu Tanjong Penegeri yang dipimpin oleh S.P.S.K. Kadar Sahib. Malah Pulau Pinang semasa itu menjadi jambatan antara dunia Melayu, benua India dan rantau Asia Barat. Jika Singapura menjadi tarikan kepada peniaga, saudagar dan cendekiawan Jawi Peranakan dan Minangkabau kepada kurun ke-19 dan 20, Pulau Pinang juga menjadi tarikan bukan hanya kepada saudagar dan peniaga tetapi juga penulis dan wartawan yang mempunyai kaitan etnik dan budaya Arab-Parsi-India serta alam Melayu terutama sekali Pulau Sumatera. Pulau Pinang adalah pusat komunikasi dan informasi penjajahan dan ini digemblengkan dengan ekspresi dan pengucapan kaum Jawi Peranakan dan Hadhrami. Kegiatan penerbitan dan persuratkhabaran Jawi Peranakan telah membentuk satu rangkaian penerbitan, pendidikan, kewartawanan dan pergerakan pemikiran dalam sejarah Malaysia dan alam Melayu.

\section{LATAR BELAKANG PENERBITAN DAN PERCETAKAN AWAL DI PULAU PINANG}

Satu-satunya teknologi yang memungkinkan amalan kewartawanan dan penerbitan surat khabar ialah teknologi mesin cetak yang secara langsung menghasilkan budaya baharu masyarakat di Tanjong, Pulau Pinang. Kemunculan persuratkhabaran dan aktiviti penulisan di Pulau Pinang dapat dilihat dari keadaan tersebut. Surat khabar terawal di Pulau Pinang ialah The Government Gazette (Warta Kerajaan) yang diterbitkan oleh A. J. Bone pada tahun 1 Mac 1806. Judulnya berubah menjadi Prince of Wales Island Government Gazette pada 7 Jun tahun yang sama. Dalam keluaran 17 Oktober 1807, perkataan "Government" telah digugurkan daripada judulnya dan akhbar itu terus diterbitkan di bawah pelbagai pemilik sebagai Prince of wales Island Gazette sehingga dihentikan pada bulan Ogos 1827. Cecil K. Byrd (1970) telah banyak menceritakan mengenai perolehan mesin dan alat cetak dari India bagi memudahkan amalan kewartawanan dan proses percetakan surat khabar di Pulau itu. ${ }^{3}$

Jika mesin cetak pertama di bawa masuk ke Pulau Pinang oleh Bone, mesin cetak kedua dibawa oleh para wakil London Missionary Society (Persatuan Mubaligh London) yang beribu pejabat di Melaka pada tahun 1820. Ia digunakan untuk mencetak buku dalam bahasa Inggeris dan Melayu. Beberapa tahun kemudian sebuah mesin cetak dan taip Melayu (Jawi) telah diperolehi. Bermula tahun 1834, bahan cetak dalam bahasa Melayu mula dihasilkan oleh mubaligh di Pulau Pinang. Seterusnya terdapat beberapa usaha dalam bidang kewartawanan dengan keluaran pertama akhbar Pinang Gazette $\mathcal{E}$ Straits Chronicle pada 7 April 1838. Dalam keluaran itu diumumkan oleh pencetak dan penerbitnya, William Cox bahawa mesin cetak, bahan, dan taip akhbar yang digunakan oleh Singapore Chronicle yang telah dihentikan itu telah dibawa ke Pulau Pinang untuk digunakan dalam usaha penerbitan surat khabar Pinang Gazette. (Byrd, 1970: 11). Malah semua percetakan awal di Pulau Pinang (tidak termasuk percetakan mubaligh) digunakan untuk percetakan surat khabar serta mengambil upah mencetak bahan kerajaan dan masyarakat peniaga. Ketika itu, semua cetakan surat khabar daripada syarikat percetakan dagangan dan percetakan kerajaan adalah dalam bahasa Inggeris, walaupun diketahui bahawa kerajaan telah membeli "taip Melayu” (Byrd, 1970: 12).

\section{Perdagangan, Pendidikan, Penerbitan dan Kewartawanan: Mengapa Pulau Pinang?}

Jaringan perdagangan dari Benua India dan Tanah Arab yang berpusat di Pulau Pinang telah membolehkan mereka meneroka pelbagai ruang. Sarjana Amerika Rupert Emerson (1964) 
yang menawarkan satu perspektif historiografi yang berbeza menyifatkan Pulau Pinang sebagai penjaga kepada jalan masuk ke sebelah Timur dan juga sebagai kediaman kecil bagi penduduk berbilang bangsa. Pulau Pinang, seperti negeri-negeri Selat yang lain, memiliki iklim dan suasana sosial, budaya dan kecendekiaan yang berbeza dari lain-lain negeri di Semenanjung Tanah Melayu. ${ }^{4}$

Politik di Pulau Pinang ialah politik bandar-politik kosmopolitan. Sistem pemerintahan dan undang-undang yang digubal dan dasar politik yang dijalankan ialah unuk kepentingan orang bandar. Orang bandar di Pulau Pinang ialah orang Tanjong dan kawasan-kawasan yang berdekatan. Mereka merupakan masyarakat peranakan - umumnya India, dan Arab. Mereka digelar kaum pedagang. Orang-Orang Melayu lebih cenderung tinggal di luar bandar dan tidak banyak terlibat dalam dunia perniagaan (Siti Rodziah Nyan, 2007). Dengan itu, kaum Jawi Pekan serta mereka dari bangsa lain, memainkan peranan besar dalam kehidupan sosial, politik dan ekonomi. ${ }^{5}$

Kedudukan geografi Pulau Pinang telah membolehkan pedagang dan pendakwah bermastautin di Pulau itu. Maka terjadilah proses difusi budaya, bangsa, amalgamasi dan juga asimilasi sosial dan identiti. Wujud juga perkahwinan campur antara golongan pedagang dari Benua India dan tanah Arab dengan wanita Melayu tempatan. Antara hasrat utama perkahwinan ini adalah untuk mengekalkan tempat dan status mereka sebagai ahli masyarakat di Pulau Pinang. Hal ini membawa banyak kelebihan dari segi ekonomi, politik dan budaya. Hasil daripada perkahwinan campur, terutama sekali dengan India Muslim dari India Selatan dan juga dari Hadramaut, telah membentuk satu masyarakat kacukan yang dikenali sebagai Jawi Pekan serta juga Peranakan Arab (Roff 1974, 2009; Omar Yusoff, 2010). Maka wujud dinamisme kehidupan budaya dan politik bandar yang memberi tumpuan bukan hanya kepada bidang ekonomi, malah melakar ruang pendidikan, bahasa dan budaya yang seterusnya mengasaskan satu sistem nilai yang membezakan kaum peranakan ini dengan kaum Melayu. Sistem nilai ini bersifat kosmopolitan yang membayangi perkembangan dan perubahan di dunia luar, terutama sekali di Eropah, Turki, rantau Arab, India serta Jepun. Secara langsung, Pulau Pinang menyumbang kepada citra alam Melayu.

Namun perlu diingatkan bahawa terdapat sedikit perbezaan antara kaum Jawi Pekan/ Peranakan dengan kaum Hadhrami. Kaum Jawi Pekan/Peranakan umumnya menganggap diri mereka dan sistem nilai dan budaya mereka sebagai Melayu. Mereka adalah Melayu dari segi identiti. Ini berbeza dengan kaum Hadrami yang telah berkahwin campur dengan orang Melayu-yang disebut sebagai Peranakan Arab. Mereka menolak gelaran identiti Peranakan; atau Jawi Peranakan, sambil mengekalkan identiti Arab/Hadhrami.

Dengan itu, kegiatan kecendekiaan, budaya dan dakwah anjuran kaum-kaum tersebut disalurkan melalui penerbitan, persuratkhabaran dan kewartawanan. Teknologi dan kemudahan percetakan sedia ada secara lazim mengikut konteks tersebut. Kesannya, satu budaya baharu telah terbentuk. Inilah kepentingan yang ditafsirkan semula karya-karya Roff. Teknologi dan budaya digemblengkan lalu menghasilkan satu pesona identiti yang unik. Misalnya, identiti Hadhrami. Identiti mereka disalurkan oleh para pencetak, pedagang dan wartawan Hadhrami melalui penyebaran dan penjualan risalah-risalah dakwah, lalu memperkukuhkan diri mereka sebagai sumber kepakaran dalam ilmu Islam (Roff, 2009: 166). Kesarjanaan dan karya Islam yang dicetak oleh penerbitan Hadhrami di Pulau Pinang bukan hanya untuk kegunaan kaum Arab sahaja tetapi juga untuk bacaan masyarakat penutur bahasa Melayu dan orang Islam yang membaca tulisan Jawi. 
Kaum Hadhrami adalah mereka yang berlayar dari semenanjung Tanah Arab, terutama dari rantau Hadhramaut lalu membawa agama Islam serta gelaran, biasanya Sayyid atau Shaykh. Mereka telah berulang-alik ke Kepulauan Melayu sejak lebih dari 1400 tahun lalu. ${ }^{6}$ Kepada masyarakat Melayu, gelaran tersebut lebih kepada menganggap golongan Hadhrami ini sebagai bangsa Arab yang berkedudukan tinggi dan terhormat. Dalam konteks ini, semua orang Arab, tidak kira dari mana asal usul mereka, adalah pewaris langsung kepada Islam, terutama sekali golongan sayyid yang dianggap sebagai keturunan Rasulullah. Golongan sayyid dilihat sebagai golongan alim dan "memiliki tahap keimanan yang unggul." ("... as possessed of unexampled piety...) (Roff, 2009: 81). Masyarakat Melayu menganggap kaum Hadhrami ini sebagai amat berpengaruh dalam setiap lapisan masyarakat.

Percetakan dan persuratkhabaran Melayu di Pulau Pinang yang dipimpin oleh kaum Jawi Peranakan dan Hadhrami bermula pada lewat abad ke 20. Ini kemudiannya diikuti oleh orang Rawa yang bermastautin di kawasan rantau Minangkabau di Sumatera menghala ke Sumatera utara. Persuratkhabaran Melayu di Pulau Pinang pada tahun 1920-an dan 1930-an terdiri daripada alim ulama, pengusaha mesin cetak dan pedagang, serta wartawan dari Sumatera dan lain-lain daerah di Hindia Timor Belanda. Perjuangan idea nasionalisme menjadi agenda utama mereka (Lubis, 2009).

Mengapakah Pulau Pinang menjadi tumpuan persuratkhabaran dan kewartawanan oleh kaum Jawi Peranakan dan Hadrami? Selain daripada hujah Emerson (1937), Pulau Pinang merupakan ruang pertembungan antara perluasan pengaruh Eropah dan diaspora Melayu, Jawi Peranakan dan Hadhrami. Kedua-dua identiti ini menggunakan teknologi percetakan yang ada untuk mewajahkan etnisiti dan identiti yang menjadi sandaran mereka. Oleh itu, prasarana di Pulau Pinang pada era tersebut telah menyediakan saluran komunikasi baharu dalam persekitaran tempatan. Satu rangkaian penerbit dan penerbitan mula wujud.

Bagi memahami kewujudan persuratkhabaran dan kewartawanan di Pulau Pinang, kita menyorot kepada sejarah perkembangannya di kepulauan Melayu. Aktiviti percetakan yang bermula sejak abad ke-15 merupakan pencetus kepada pertumbuhan maklumat, ilmu, nilai dan budaya. Malah percetakan telah menginjak pandangan sarwa tamadun moden. Dalam dunia Islam, terutamanya di Mesir, dan kemudiannya di Kepulauan Melayu, aktiviti percetakan telah membawa kepada perkembangan serta penerbitan ilmu dalam pelbagai bidang seperti falsafah dan syariah, politik dan ekonomi. Satu lagi ciri penerbitan surat khabar di Kepulauan Melayu ialah proses penghasilannya adalah didorong oleh pengenalan kepada teknologi dan kepentingan percetakan dalam tamadun moden (Roff, 1967: 43-55).

Beberapa faktor telah menyumbang kepada perkembangan fenomena persuratkhabaran dan kewartawanan di Pulau Pinang. Antaranya ialah dakwah Islam dan pendedahan Islam kepada masyarakat umum yang membawa kepada kewujudan wacana dalam bentuk khutbah, dakwah dan penceritaan. Material ini kebanyakannya dimuatkan sebagai bahan bacaan dalam bentuk bercetak; dan kaum Jawi Peranakan memainkan peranan utama dalam menggerakkan penerbitan surat khabar di Pulau Pinang. Dari perspektif sejarah, surat khabar Melayu yang dikendalikan oleh kaum Jawi Peranakan mula berkembang sejak lewat abad ke19. Perkembangan di Singapura telah banyak mempengaruhi Pulau Pinang; dan sebaliknya (Roff, 1974; A.F. Yassin, 1986; Ahmat Adam, 1994; Mohd. Safar Hasim, 2004; Mazlan Nordin, 2009). Perkembangan itu juga banyak berkait dengan aspek maritim. Pulau Pinang terletak di antara lautan Hindi dan laut China Selatan dan kedudukan ini menghubungkan Kepulauan Melayu dengan Benua India dan Tanah Arab. Kesibukan Pulau Pinang bukan hanya kerana 
menjadi tumpuan kegiatan perdagangan, tetapi sebagai pusat penyebaran Islam. Tanjong terutama sekali menyaksikan perkembangan penduduk peranakan India dan peranakan Arab. Dalam kalangan penduduk yang pelbagai itu, mereka menggunakan bahasa Melayu dalam interaksi seharian dan dalam aktiviti wacana agama, budaya dan kecendekiaan.

\section{Jawi Pekan, Jawi Peranakan dan Jawi Peranakan ${ }^{7}$}

Pada tahun 1876, Kepulauan Melayu menyaksikan penerbitan surat khabar Jawi Peranakan yang bertempat di Singapura. Jawi Peranakan, sebuah penerbitan mingguan, dianggap sebagai surat khabar Melayu pertama dalam sejarah dan persejarahan Malaysia. Kaitan masyarakat Jawi Peranakan dan kemunculan surat khabar Jawi Peranakan merupakan satu perkembangan semula jadi, iaitu satu jelmaan sementara pada ketika wujud kehidupan Melayu di kawasan bandar.

Asalnya dari istilah Jawi Pekan, identiti yang diberikan kepada orang Melayu (Jawi) bandar (Pekan) oleh pedagang dan masyarakat Arab, kesedaran diri identiti itu tidak terserlah sepanjang zaman. Malah, detik zaman, konsep dan amalan Jawi Peranakan dan surat khabar Jawi Peranakan sudah berlalu. Kesedaran identiti yang ada diasak oleh pelbagai rasa, rupa dan jiwa arus-arus ruang dan masa. Namun, pada satu ketika dahulu, penerbitan surat khabar Jawi Peranakan, dan seterusnya beberapa lagi surat khabar, majalah dan syarikat penerbitan dan percetakan khususnya di Singapura dan Pulau Pinang membuktikan perhubungan akrab aktiviti penulisan, persuratkhabaran, perniagaan, ekspresi budaya dan politik dengan kaum tersebut.

Malah, kemunculan surat khabar dan majalah hanya menunjukkan kemajuan dan kesejahteraan, serta kecendekiaan kaum Jawi Peranakan dalam konteks arus perubahan yang pesat dengan kemasukan pengaruh Eropah dan pertembungan pembaratan dengan Islam dan tradisi Melayu. Surat khabar dan majalah dilihat sebagai satu kesinambungan kewujudan budaya dan pemikiran masyarakat Jawi Peranakan di Kepulauan Melayu, sebagai menyahut gelombang kosmopolitanisme yang amat dirasai dan dibimbangi. Bagi melindungi dan meningkatkan ketahanan identiti mereka, pada tahun 1876, masyarakat Jawi Peranakan telah menubuhkan sebuah persatuan di Singapura dengan nama yang sama (Roff, 1967: 48). Seterusnya, Persatuan Jawi Peranakan dipertanggungjawab mengendalikan sebuah percetakan dan menerbitkan sebuah akhbar mingguan dalam bahasa Melayu.

Tindakan tersebut adalah akibat satu kesedaran dan takrif identiti. Jawi Peranakan merupakan satu bentuk formasi budaya dan identiti yang muncul di Singapura, Pulau Pinang dan Melaka bermula pada abad ke 19. Masyarakat Jawi Peranakan ini dinyatakan sebagai mempunyai mobiliti sosial yang tinggi disebabkan tahap literasi dan pendidikan yang sesuai dengan keadaan baharu dengan munculnya pentadbiran penjajahan, serta kefasihan mereka dalam bahasa Inggeris dan kebolehan dalam penterjemahan bahasa Inggeris dan bahasa Melayu. Sejak zaman awal penjajahan Inggeris sehingga kemunculan Perang Dunia Kedua, ahli masyarakat Jawi Peranakan telah memainkan peranan kepimpinan budaya dan politik Melayu dalam memberi kesedaran kepada proses pembentukan negara bangsa.

Satu catatan terawal pada lewat abad ke-19 tentang surat khabar Melayu pertama telah menceritakan bahawa Jawi Peranakan "memuatkan berita dalam dan luar negeri yang terbaru, menolong memajukan pelajaran anak negeri, dan membantu memberikan keselarasan kepada bahasa Melayu yang sedang menempuh perubahan." Surat khabar Jawi 
Peranakan diterbitkan setiap hari Isnin dan dicetak dalam huruf timah dengan menggunakan tulisan Jawi oleh Matba' al-Saidi (percetakan Muhammad Said) di No.431, Victoria Street (Kampung Gelam), Singapura. Surat khabar yang bercogankan "Tawakal itu sebaik-baik Bekal" mengandungi empat halaman. Harga langganannya ialah lima ringgit setahun atau tiga ringgit untuk enam bulan manakala harga senaskhah pula ialah 30 sen. Namun, harga ini diturunkan ke 15 sen sepuluh tahun kemudian. Jawi Peranakan, seperti surat khabar lain di negeri-negeri Selat juga menerima iklan (Roff, 1967: 51-52).

Dalam konteks Pulau Pinang, yang menarik ialah walaupun Jawi Peranakan beribu pejabat di Singapura, akhbar ini mempunyai wakil penjual dan pewarta di Pulau Pinang, selain di beberapa tempat di semenanjung Tanah Melayu, Riau, Padang, Sarawak dan Pulau Jawa. Cerita-cerita yang disiarkan meliputi kejadian yang berlaku di negeri-negeri Melayu Semenanjung dan di daerah lain seperti Lingga, Jawa Barat, Sumatera Utara (Aceh), Sumatera Barat (Padang), Sumatera Timur (Deli dan Serdang) dan juga Brunei. Pengarang dan wartawan akhbar Jawi Peranakan, yang pada umumnya terdiri dari kaum Jawi Peranakan menulis sebagai orang Melayu dan meletakkan kepentingan mereka bersama-sama dengan kepentingan orang Melayu (Roff, 1967: 48).

Jawi Peranakan telah diterbitkan tanpa gangguan selama dua puluh tahun. Akhbar ini telah mendapat sambutan yang baik dalam kalangan pembaca Melayu, Arab dan Jawi Peranakan sendiri (Roff, 1967:49). Jawi Peranakan dapat dianggap sebagai simbol ekspresi politik dan budaya kemunculan sebuah masyarakat baharu. Malah, akhbar ini ialah tanda kesedaran yang ditonjolkan sebagai satu fenomena sosial dan budaya melalui berita, makalahmakalah berbentuk rencana dan komentar serta syair. Jawi Peranakan boleh dianggap sebagai usaha pertama sebuah masyarakat Melayu-Islam, yang dikenali sebagai Jawi Peranakan, untuk melapor dan mengulas keadaan kehidupan masyarakat tanpa ditentukan oleh tradisi lampau atau keadaan semasa yang memperlihatkan pengaruh kemunculan budaya dan gaya hidup Eropah.

Pengarang Jawi Peranakan biasanya mengambil jalan tengah. Seperti juga masyarakat Jawi Peranakan, identiti surat khabar Jawi Peranakan bersifat objektif — seperti juga Abdullah Munsyi sebelumnya-tidak terikat kepada gaya genre dan amalan lama. Pada masa yang sama, mereka sedar tentang 'bangsa' dan bahasa mereka. Perlu diingatkan bahawa dalam tempoh tiga puluh tahun setelah terbitnya Jawi Peranakan, semenanjung Tanah Melayu dan Kepulauan Melayu menyaksikan 16 buah surat khabar dan majalah dalam bahasa Melayu yang diterbitkan, tujuh buah di Singapura, lima buah di Pulau Pinang, dan empat buah di Perak. Umumnya, pengarang, penerbit dan pencetak terdiri daripada ahli masyarakat Jawi Peranakan (Roff, 1967: 49)

Satu pendekatan dalam merangka kewartawanan dan persuratkhabaran sebagai manifestasi identiti Jawi Peranakan dan surat khabar Jawi Peranakan adalah dengan melihatnya sebagai satu evolusi dan transformasi dalam masyarakat Melayu. Kewartawanan masyarakat Jawi Peranakan, menerusi surat khabar Jawi Peranakan dapat disifatkan sebagai kesinambungan pertembungan Melayu-Islam dengan dunia Eropah. Selain daripada menjadi satu saluran perdagangan dan perniagaan, yang penting ialah peranannya yang menjadi pengantara untuk ekspresi budaya dan politik. Jelas, apa-apa yang dikatakan sebagai debat Melayu bermula lebih awal menerusi penerbitan surat khabar Melayu seperti Jawi Peranakan.

Genre ini digunakan oleh Abdullah Munsyi, seorang tokoh Jawi Peranakan dari Melaka dan 27 tahun sebelum itu oleh seorang lagi tokoh terkenal iaitu Ahmad Rijaluddin Hakim 
Long Kandu dari Kedah/Pulau Pinang. Sukar hendak dikatakan jika Abdullah Munsyi atau Ahmad Rijaluddin tidak mempengaruhi sebarang penglibatan dan pandangan golongan Jawi Peranakan Pulau Pinang, atau di Singapura terhadap kewartawanan dan persuratkhabaran selepas zaman mereka.

Malah, yang berlaku di Pulau Pinang adalah rentetan kepada yang berlaku pada awal tahun-tahun 1800-an. Dari penulisan Abdullah Munsyi dapat diteliti bahawa beliau yang juga mewakili identiti Jawi Peranakan memulakan satu institusi, serta menjadi bapa modernisme dan kewartawanan Melayu. Apabila Jawi Peranakan dikaitkan dengan tukang cerita, satu gagasan, bentuk dan identiti baharu telah muncul. Medium kewartawanan tersebut yang hadir dalam dua pesona-pertama, Abdullah Munsyi (meninggal dunia pada tahun 1826) dan kedua, surat khabar Jawi Peranakan (1876) yang merangkumi genre yang pelbagai-debat, makalah, dan khabar.

Medium persuratkhabaran oleh masyarakat Jawi Peranakan bukan sekadar melaporkan, tetapi mentafsir, memberi makna kepada peristiwa dan persekitaran. Kritikan diri sendiri amat lumrah. Tukang cerita tersebut memainkan peranan sebagai pengkritik sosial, ahli falsafah dan pemikir dalam menggunakan persuratkhabaran sebagai alat reformasi dan refleksi. Antara tahun 1876 hingga Perang Dunia Kedua, para wartawan Melayu melihat diri mereka dalam konteks alam dan Kepulauan Melayu. Ini dapat dilihat dalam surat khabar Jawi Peranakan (1876-1896), Dunia Melayu (1928) dan Paspam (1938 - ), yang menyaksikan citra identiti Jawi Peranakan dipaparkan. Akhbar Jawi Peranakan sendiri melihat dirinya bukan hanya sebagai satu institusi di Tanah Melayu tetapi juga di Kepulauan Melayu yang menempatkan wakil-wakil bukan hanya di semenanjung tetapi di Sumatera, seperti di Medan, Deli, Padang, Singkel, Riau dan juga di Sarawak. Jawi Peranakan memberi suara kepada geografi alam Melayu. Malah, Jawi Peranakan telah memainkan peranan dalam membentuk kesedaran Melayu—kesatuan, kepelbagaian, dan kemelayuan. Kewartawanan Melayu daripada naratif Abdullah Munsyi dan seterusnya kemunculan persuratkhabaran di Pulau Pinang mencerminkan kesedaran transformasi dan kesinambungan satu tradisi.

'Psyche' masyarakat Jawi Peranakan merentasi mana-mana negeri, dan umumnya melihat kedudukan mereka sebagai sebahagian daripada penduduk Kepulauan Melayu Hanya secara kebetulan sahaja pembentukan identiti Jawi Peranakan itu terserlah di Singapura dan Pulau Pinang. Namun, kebanyakan mereka yang berketurunan dari benua India mula berhijrah dari Pulau Pinang ke Taiping dan seterusnya ke lain-lain kawasan di merata Semenanjung Tanah Melayu. Peranan kaum Jawi Peranakan dalam penubuhan dan perkembangan Persaudaraan Sahabat Pena Malaya (Sahabat Pena) juga perlu diiktiraf. Dicetuskan oleh surat khabar Saudara dalam bulan Mac 1934, Sahabat Pena, telah menganjurkan persidangan kebangsaan Melayu secara besar-besaran yang pertama pada 11 November tahun yang sama_persidangan Melayu yang pertama di Malaya (Roff, 1967: 215, 216).

Antara tokoh yang hadir ialah S.M.Zainal Abidin, seorang Jawi Peranakan daripada Pulau Pinang, yang kemudiannya menjadi presiden pertama Sahabat Pena dan Hamidun bin Mohd, Hashim, seorang lagi Jawi Peranakan yang kemudiannya aktif di cawangan Selangor. Zainal Abidin bin Sutan Maidin (atau S.M.Zainal Abidin) merupakan seorang guru, penulis dan ahli politik yang dilahirkan di Pulau Pinang pada tahun 1898 (Roff, 1967:216, nota kaki 10). Beliau memperjuangkan kemajuan budaya dan persuratan Melayu, serta banyak menyumbang penulisan kepada akhbar dan majalah, dan diketahui umum sebagai seorang modernis. Seorang lagi Jawi Peranakan yang aktif sebagai guru, pendakwah, penulis dan 
penerbit ialah K. Sultan Merican. Beliau memulakan jurnal yang bertajuk Islamic Voice of Malaya semasa zaman sebelum Perang (Merican, 2010: 57-70). Jurnal itu menjadi alat yang digunakan dalam perjuangan politik menentang Malayan Union. Di Pulau Pinang, peranan kaum Jawi Peranakan dalam mengendalikan dan menerbit majalah dan surat khabar telah membentuk cara berfikir penduduk di kawasan-kawasan sekitarnya.

Pengarang dan wartawan Jawi Peranakan telah menjadikan Islam sebagai wadah untuk mereka mentakrif makna istilah 'Melayu.' Dalam persoalan memajukan identiti, masyarakat Jawi Peranakan menganggap diri mereka sebagai 'Melayu.' Faktor yang merentasi identiti itu ialah Islam. Adakalanya mereka asing kepada Melayu, pada masa yang sama sebahagian dari Melayu dan kemelayuan. Pada masa akan datang, kita akan berdepan dengan perubahan kepada jiwa, rupa dan rasa sesuatu identiti yang ada kini. Waktu 'kemuncak' kesedaran Jawi Peranakan dalam sejarah Melayu mungkin sudah berlalu. Namun, kita sering dengar daripada pertuturan dan perbualan Melayu Tanjong: "Kita semua orang Melayu."

\section{KEWARTAWANAN DAN PENERBITAN AWAL KAUM JAWI PERANAKAN DI PULAU PINANG}

Lebih dari 20 penerbitan berbentuk dan bersifat kewartawanan wujud di Pulau Pinang sebelum era surat khabar arus perdana dalam dekad 1930-an. Surat khabar pertama ialah Tanjong Penegeri, yang diterbitkan dua kali seminggu antara 1894-95. Mula diterbitkan pada 4 Oktober 1895, surat khabar Melayu pertama di Pulau Pinang, yang dipimpin oleh S.P.S.K. Kadar Sahib iaitu seorang Jawi Peranakan, menggunakan huruf Jawi dan mengandungi empat halaman. Edaran akhbar ini sampai ke Brunei dan Sri Lanka. Isi kandungannya meliputi berita tentang Kedah, berita yang dikutip daripada beberapa surat khabar di Sumatera, rencanarencana mengenai peperangan China dan Jepun, negeri-negeri Asia Barat dan Eropah serta iklan dan khabar perniagaan. Pada 4 Mac 1895, Tanjung Penegri dicetak buat kali terakhir. Seterusnya, kewartawanan Jawi Peranakan memperlihatkan Pemimpin Warta (1895-1897) dan Lengkongan Bulan (1900-1901). Ketiga-tiga penerbitan dicetak dengan litograf tangan yang merangkumi empat halaman. Menurut Roff, walaupun berita tempatan dan komentar dalam penerbitan-penerbitan tersebut tidak seberapa, namun amat membantu sejarawan mengisi ruang peristiwa di antara pemberhentian penerbitan surat khabar di Singapura antara tahun tamatnya penerbitan Jawi Peranakan dan permulaan penerbitan Taman Pengetahuan dalam tahun 1904.

Pada bulan Mac 1900, surat khabar Pulau Pinang pertama yang dicetak (berbeza daripada kegunaan litograf sebelumnya) ialah mingguan Bintang Timor. Akhbar ini dihentikan selepas 30 keluaran dan digantikan oleh Chahaya Pulau Pinang. Surat khabar tersebut dicetak sehingga lapan setengah tahun iaitu sehingga bulan Mac 1908 dan merupakan surat khabar Pulau Pinang yang paling berjaya sehingga kemunculan Saudara pada tahun-tahun 1930an. Chahaya Pulau Pinang memuatkan hal ehwal Empayar Uthmaniyah yang mengalami zaman kejatuhan. Penerbitan itu juga melaporkan dengan panjang lebar mengenai dunia Arab di Asia Barat (Timur Tengah pada masa itu) dengan seringkali menterjemah bahagianbahagian surat khabar Mesir dan penerbitan kewartawanan lain di dunia Arab. Chahaya Pulau Pinang mempamerkan perubahan tumpuan dan gaya dalam kewartawanan Melayu. Pada 4 November 1895, lapan bulan setelah terbitnya Tanjong Penegeri, muncul Pemimpin Warta sebagai surat khabar yang kedua di Pulau Pinang. Akhbar ini memuatkan berita-berita tempatan; berita luar negeri yang dikutip daripada akhbar-akhbar Inggeris juga disiarkan, 
selain menyiarkan harga barangan di pasar serta iklan. Untuk memenuhi selera para pembaca beragama Islam, berita mengenai peperangan Turki dengan Greece juga disiarkan. ${ }^{8}$

Pemberitaannya mengenai masyarakat sezaman yang merangkumi kejadian-kejadian yang melibatkan kaum Melayu, Cina dan India jelas menunjukkan ciri-ciri yang amat menarik pada akhbar Pemimpin Warta. Pengarangnya, Mohd. Ally bin Haroon al-Hindi, ternyata mewarisi semangat Jawi Peranakan Abdullah Munsyi, dengan memaparkan jiwa kebangsaan 'Melayu,' sehinggakan beliau menyatakan pemerhatiannya:

... Akan tetapi kita perhatikan tatkala mereka telah faham di dalam pelajaran Inggeris itu hampir-hampir akan membuang adat-adat orang tua-tua kita baik daripada pakaian, pertuturan, perjalanan dan sebagainya. Walhal jika mereka terlatih dahulu faham di dalam ilmu dan nasehat daripada kitab-kitab daripada ulama pada agak kita tentulah bertambah baik pekerti dan sebagainya... (Pemimpin Warta No.31, Jun 1896).

Tujuan utama penerbitan beberapa surat khabar tersebut adalah untuk menyatupadukan masyarakat Jawi Peranakan yang tinggal di Tanjong dan persekitarannya. Surat khabar itu juga berfungsi sebagai media berita yang penting ketika itu, walaupun liputan beritanya lebih merupakan terjemahan daripada surat khabar Inggeris (Siti Rodziyah Nyan, 2007).

\section{W. R. ROFF, KEWARTAWANAN BAHASA MELAYU DAN KEWARTAWANAN HADHRAMI}

Makalah ini dan banyak penulisan seumpamanya bergantung kepada dedikasi dan iltizam W.R. Roff dalam usaha etnografi dan empiris beliau mendalami masyarakat dan pemikiran Melayu yang secara tidak langsung turut tertumpu kepada kewartawanan dan persuratkhabaran Melayu. Roff telah meluangkan lebih dari 40 tahun meneliti dan menulis mengenai sejarah moden Islam dan Islam dan masyarakat Melayu di Asia Tenggara. Tumpuan khususnya ialah kepada sejarah sosial dan intelektual. Mendiang Roff merupakan Emeritus Profesor Sejarah di Columbia University, dan Felo Profesor Kehormat dalam Kajian Timur Tengah dan Islam di University of Edinburgh. Beliau meninggal dunia pada 3 Mei 2013 di Scotland.

Orang Melayu terhutang budi kepada sejarawan Roff kerana wacana beliau begitu prihatin mengenai pertembungan dunia Melayu dan Barat terutama sekali di Singapura, serta penelitiannya mengenai asal-usul persuratkhabaran Melayu. Kita dapat mengenal pasti satu jurai yang perlu diakui oleh para pengkaji dan ini merujuk kepada sejarah dan persejarahan Melayu yang umumnya menyatakan bahawa persuratkhabaran Melayu bermula dengan Jawi Peranakan pada tahun 1876 dan memuncak dengan akhbar-akhbar besar pada tahun 1930-an sehingga muncul surat khabar Utusan Melayu tahun 1939.

Pada tahun 2005, Roff dalam satu Persidangan Antarabangsa mengenai YemeniHadrami di Asia Tenggara: Pengekalan atau asimilasi Identiti? ${ }^{9}$ menyorot konteks yang lebih luas kewartawanan Melayu dan Arab sekitar lewat abad ke-19 dan awal abad ke20 yang dimulakan dan diperkembang oleh penglibatan kaum Hadhrami. Roff melihat fenomena yang berlaku pada masa itu sebagai sesuatu yang menakjubkan. Kewujudan kewartawanan tersebut, seperti yang dibincangkan lebih awal dikaitkan dengan pengenalan 
teknologi media cetak, perkembangan literasi masyarakat awam dan perasaan anti penjajah. Roff melihat fenomena yang serupa turut berlaku di dunia Arab. Selain menyebut pertumbuhan dan perkembangan persuratkhabaran di bawah naungan kaum Hadhrami di Singapura dan di Perak,10 Roff (2009: 170) turut menyentuh keadaan itu di Pulau Pinang dikenal pasti sebagai fasa kedua penglibatan kaum Hadhrami dalam kewartawanan dan persuratkhabaran di Malaya. Antara tahun 1925 dan 1939, sebanyak 29 majalah dan surat khabar Hadrami dapat dikenal pasti: 16 dalam Bahasa Melayu dan 13 dalam bahasa Arab. Dalam jangka masa tersebut, penerbitan yang pertama muncul dari Madrasa al-Mashhur al-Islamiya di Pulau Pinang. Al-Raja diterbitkan sebulan sekali dari Mac 1925 sehingga 1928. Kandungannya mencerminkan agenda islah yang berkait dengan al-Mashhur. Sebuah lagi ialah Wahdar al-Madaris, juga diterbitkan di al-Mashhur di Pulau Pinang bermula tahun 1935 sebanyak tiga bulan sekali. Akhbar ini diterbitkan bagi pihak Jama'ah Guru-Guru Agama Semenanjung Melayu dan disunting oleh Shaykh Muhammad Husayn Rafie. Majalah tersebut menggelarkan dirinya sebagai "majalah yang pertama sepertinya, diterbitkan sekali tiga bulan oleh guru-guru sekolah-sekolah bahasa Arab." (Roff, 2009: 170).

Penerbitan seperti itu menunjukkan penekanan kaum Hadhrami kepada reformasi pendidikan Islam dan modenisasi dalam masyarakat Melayu. Ini dilihat pula dengan satu perkembangan yang baharu dalam kewartawanan Hadhrami yang menggunakan bahasa Melayu-kemunculan surat khabar harian dan mingguan serta majalah komentar, yang dibaca dengan luas di semenanjung dan menyumbang kepada pertumbuhan nasionalisme politik Melayu. Perubahan ini kelihatan dalam surat khabar Saudara pada Januari 1932. Editornya ialah Mohd. Yunus b Abdul Hamid, 1928-31; Sayyid Alwi b. Sayyid Syaikh al-Hadi, 1930-Feb. 1933, Mac 1934-pertengahan 1936; Sayyid Shaykh b Ahmad al-Hadi, Feb, 1933Feb. 1934; Abdul Wahab b Abdullah, Feb 1933-Mac 1934; Shaykh Mohd. Tahir Jalaluddin, Mac-Sept 1934; Abdul Majid b Sabil, pertengahan tahun 1936-Jun 1939; dan Mohd. Amin b Nayan, lewat tahun 1939-1941. Saudara yang diasaskan oleh Sayyid Shaykh b Ahmad alHadi dicetak oleh Jelutong Press sehingga tahun 1939 (Roff, 1972: 41-42). Seperti kebanyakan pemilik surat khabar dan percetakan kaum Hadhrami, al-Hadi mengambil ramai wartawan dari Sumatra, serta mengedar surat khabar mereka di seluru semenanjung. Salah seorang daripadanya ialah Abdul Wahab Abdullah, datuk saudara al-Hadi. Aktiviti percetakan dan penerbitan bertumpu di Lebuh Acheen dan di Jelutong. Dari satu segi, Lebuh Acheen merupakan "Fleet Street ${ }^{11}$ kepada percetakan surat khabar dan karya kesusasteraan berbahasa Melayu dan Arab" (Khoo, 1990: 29)

Seperti juga surat khabar harian Warta Malaya dan mingguan Lembaga Melayu, yang kedua-duanya diterbitkan di Singapura, surat khabar Saudara memainkan peranan dan sumbangan yang penting kepada pertumbuhan identiti Melayu. Saudara lebih pro-Melayu daripada bersifat anti-penjajahan. ${ }^{12}$ Pesaing Saudara ialah Majlis yang diterbitkan di Kuala Lumpur. Sebuah lagi penerbitan bulanan muncul di Pulau Pinang pada September 1926. Al-Ikhwan di bawah pimpinan Syed Syakh b Ahmad al-Hadi kekal selama lebih lima tahun. Akhbar ini dipaparkan sebagai sebuah penerbitan Islam dengan tujuan islah selain memperjuangkan isu-isu sosial dan politik. Antara kandungannya ialah tema kebebasan wanita dan desakan supaya diberi lebih pendidikan Inggeris kepada orang Melayu. Bersama dengan surat khabar Saudara, kedua-dua penerbitan ini yang dicetak oleh Jelutong Press dilihat sebagai penyuntik kepada kebangkitan semangat nasionalisme Melayu (Roff, 1972: 12). 


\section{KESIMPULAN}

Kajian lanjutan perlu dilaksanakan bagi menghalusi falsafah dan pandangan sarwa kewartawanan dan persuratkhabaran Melayu sebelum kemunculan Utusan Melayu pada tahun 1939. Sejarah dan penulisan sejarah oleh para pengkaji sejarah kewartawanan dan persuratkhabaran Melayu perlu meneliti bukan hanya teks tetapi konteks pada jangka masa tertentu di negeri-negeri Selat seperti Pulau Pinang serta sejarah di kawasan lain di dunia_terutama sekali dalam hal ini, keadaan dan iklim politik dan pemikiran di rantau Hadhramaut, India, Eropah dan Empayar Uthmaniyah. Hasil pertembungan budaya dan ekspresi peranakan yang terlihat di Pulau Pinang boleh dikaji dalam konteks kepelbagaian Melayu dan kemelayuan. Berdasarkan kajian sebegini, kita dapat melihat pelbagai lapisan sejarah kewartawanan Melayu dan bagaimana praktiknya mencetus kesedaran mengenai identiti Melayu melalui gelaran DKK (Darah Keturunan Keling) dan DKA (Darah Keturunan Arab). Pengaruh kewartawanan dan persuratkhabaran Jawi Pekan dan Hadhrami, jika dilihat pada panggilan-panggilan tersebut amat kuat mempengaruhi sudut pandang alam Melayu sehingga berpengaruh besar dalam mencorakkan perjuangan dan sifat surat khabar Melayu selepas Perang Dunia Kedua. Hasil penelitian dan penulisan Roff mesti ditelaah semula bagi memahami dan mentafsir dengan lebih rencam dan luas suasana dan jalinan identiti berhubung sejarah kewartawanan dan persuratkhabaran di Malaysia. 


\section{NOTA}

1 Ini bermaksud kegunaan bahasa serta kesedaran citra terhadap Melayu dan Kemelayuan yang ditonjolkan oleh masyarakat Melayu Tanjong atau Jawi Pekan/Peranakan pada lewat abad ke 19 sehingga penaklukan Jepun tahun 1942. Dalam makalah ini istilah 'Melayu Tanjong' membawa maksud yang sama dengan Jawi Pekan/Peranakan. Ia boleh digunakan saling berganti.

2 Di Tanjong, Pulau Pinang pada masa itu, kita dapat lihat satu pembentukan masyarakat berdasarkan kepada Islam dan masyarakat setempat, yang umumnya Melayu dan hasil persemendaan antara wanita Melayu dengan lelaki India Muslim khususnya dari Pantai Koromandel dan Pantai Malabar di India Selatan. Ada juga hasil perkahwinan dengan masyarakat Arab yang berlabuh di Pulau Pinang sejak lebih dari 250 tahun yang lalu. Asimilasi dikalangan kaum India Muslim dengan Arab, atau Peranakan Arab telah memberi satu lapisan identiti kepada masyarakat di situ.

$3 \quad$ Lihat Cecil K. Byrd (1970). Percetakan awal di Jajahan Selat (Ter. Mansor Ahmad Saman, 1991). Kuala Lumpur: Dewan Bahasa dan Pustaka, h. 4-12.

4 Lihat Rupert Emerson (1964) Malaysia: A Study in Direct and Indirect Rule. (Kuala Lumpur: University of Malaya Press). Untuk perbincangan lebih lanjut, rujuk halaman 63-111.

$5 \quad$ Lihat Penang past and present 1786-1963: a historical account of the City of George Town since 1786 (1966). Pulau Pinang: City Council of George Town, h. 25.

6 Begitu juga dengan pelayaran mereka ke Pantai Malabar dan Koromandel di selatan India, serta ke sepanjang pantai timur di benua Afrika.

7 Bahagian ini banyak disesuaikan daripada sebahagian Bab 5 Masyarakat dan Suratkhabar Jawi Peranakan: Ekpresi Satu Identiti oleh Ahmad Murad Merican (2010), dalam Omar Yusuf dan Jamaluddin Aziz, ed. Jawi Peranakan di Pulau Pinang: Ekspresi sebuah identiti. Minden: Penerbian Universiti Sains Malaysia.

$8 \quad$ Lihat A.M. Iskandar (1976) dan Roff (1972).

9 International Conference on Yemeni-Hadramis in Southeast Asia: Identity Maintenance or Assimilation? Bertempat di Universiti Islam Antarabangsa, Ogos 2005. Lihat W. R. Roff (2009). Studies on Islam and society in Southeast Asia. Singapore: NUS Press. Kertas kerja itu diterbitkan sebagai "The Ins and Outs of Hadhrami Journalism in Malaya, 1900 - 1941: Assimilation or Identity Maintenance?," bab 9, halaman 165-175. Bahagian ini banyak bergantung kepada bab tersebut kecuali dipetik sebaliknya. 10 Dari jumlah 22 majalah dan suratkhabar dalam bahasa Melayu dan Arab yang diterbitkan di Singapura dan negeri-negeri Melayu di Barat semenanjung sehingga tahun 1910, tujuh adalah di bawah naungan kaum Hadrami. Tiga buah diterbitkan di Perak: Seri Perak dan Jajahan Melayu di Taiping (masing-masing 1891 dan 1896-97), dan Khizanah al-Ilmu (1904) di Kuala Kangsar. Seri Perak dan Jajahan Melayu dipimpin dan disunting oleh Sayyid Abdul Hassan bin Burhan. Penyunting Khizanah al-Ilmu ialah Sayyid Abdullah b Abu Bakar al-Attas. Roff juga menjelaskan kedudukan al-Imam (190608) di Singapura yang ditafsirkannya sebagai mencerminkan perkongsian budaya dalam kerangka Islam moden.

11 Merujuk kepada amalan kewartawanan dan penerbitan akbar di London, England.

12 Pesaing Saudara ialah Majlis yang diterbitkan di Kuala Lumpur. Dilihat dari perspektif Melayu, walaupun Majlis dipimpin oleh dua wartawan Melayu yang berwibawa dan terkemuka, Abdul Rahim Kajai dan Othman Kalam, ia dimiliki oleh seorang Jawi Peranakan yang bernama Muhammad Amin bin Yusoff. 


\section{RUJUKAN}

Ahmat Adam (1992). Sejarah dan bibliografi akhbar dan majalah Melayu abad kesembilan belas. Bangi: Universiti Kebangsaan Malaysia.

A M Iskandar Haji Ahmad (1976). Persuratkhabaran Melayu 1876-1968. Kuala Lumpur: Dewan Bahasa dan Pustaka.

Cecil K. Byrd (1970). Percetakan awal di Jajahan Selat (Terj. Mansor Ahmad Saman, 1991). Kuala Lumpur: Dewan Bahasa dan Pustaka

Emerson, Rupert (1964) Malaysia: A study in direct and indirect rule, New York: Macmillan Co. . Emerson, Rupert (1993). Malaysia. Kuala Lumpur: Dewan Bahasa dan Pustaka.

Harper, T. N. (2001). The state and information in modern Southeast Asia history. Dlm. Yao Souchou, (ed.). House of glass: culture, modernity and the state in Southeast Asia (h. 213-240). Singapore: Institute of Southeast Asia Studies.

Khoo Su Nin (1990). A guide to the local way of life and culture of Penang. Pulau Pinang, 2 (2), 12-29.

Lubis, Abdur-Razzaq (2009). The legacy of Sumatran trade and knowledge networks in Penang, in Wazir Jahan Karim, ed. Straits Muslims: Diapsoras on the Northern Passage of the Strait of Malacca, Georgetown: INAS.

Merican, Ahmad Murad (2010), Masyarakat dan Surat Khabar Jawi Peranakan: Ekspresi suaru identiti. Dalam. Omar Yusoff dan Jamaluddin Aziz, ed. (2010) Jawi Peranakan di Pulau Pinang: Ekspresi sebuah identiti (h. 57-70). Minden: Penerbit Universiti Sains Malaysia .

Mohd Safar Hasim (1996). Akhbar dan kuasa: perkembangan sistem akhbar di Malaysia sejak 1806. Kuala Lumpur: Penerbit Universiti Malaya

Omar Yusoff \& Jamaluddin Aziz, ed. (2010) Jawi Peranakan di Pulau Pinang: Ekspresi sebuah identiti. Minden: Penerbit Universiti Sains Malaysia

City Council of George Town, (1966). Penang past and present 1786-1963: a historical account of the City of George Town since 1786. Pulau Pinang: City Council of George Town.

Proudfoot, I (1993). Early Malay printed books. Kuala Lumpur: Academy of Malay Studies dan The Library, University of Malaya).

Roff, W.R. (2009). Studies on Islam and Society in Southeast Asia. Singapore: NUS Press.

Roff, W.R. . (1974). The origins of Malay nationalism. Kuala Lumpur: University of Malaya Press.

Roff, W.R. . (1972). Bibliography of Malay and Arabic periodicals published in the Straits Settlements and Peninsular Malay States 1876-1941. London: Oxford University Press.

Roff, W.R. . (1967). Sejarah surat-surat khabar Melayu. Kuala Lumpur: Universiti Malaya.

Siti Rodziyah Nyan (2007). Pulau Pinang sebagai pusat kecemerlangan akhbar-akhbar Melayu. Dlm. Sohaimi Abdul Aziz, (ed.) Dari Tanjung Penaga ke Georgetown: Membongkar sejarah negeri Pulau Pinang. Pulau Pinang: Kementerian Kebudayaan, Kesenian dan Warisan Malaysia dan Persatuan Karyawan Pulau Pinang. 